\title{
Risk factors and experiences of prepartum depression among pregnant women in urban- low income in Nairobi Kenya: a
}

\section{mixed-method study [version 1; peer review: 1 approved with}

\section{reservations, 1 not approved]}

\author{
Beatrice A. Madeghe (D1, Wambui Kogi-Makau (D1, Sophia Ngala1, Manasi Kumar2 \\ ${ }^{1}$ Department of Food Science Nutrition and Technology, University of Nairobi, Nairobi, 00625, Kenya \\ ${ }^{2}$ Department of Psychiatry, College of Health Sciences, University of Nairobi, Nairobi, 00100, Kenya
}

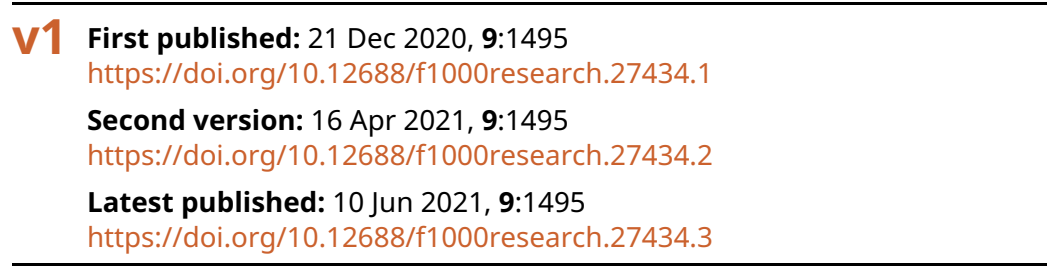

\section{Abstract}

Background: Prepartum depression is common among pregnant women and has not been studied much in low and middle-income countries. Evidence shows that mental illnesses are more prevalent in urban than in rural areas. The study objective was to determine the magnitude of prepartum depression, risk factors, and real-life experiences of depression among pregnant women.

Method: A mixed-method cross-sectional study was conducted. It included 262 pregnant women attending antenatal clinics in two public health facilities in the urban low-income settlement of Nairobi, Kenya. Edinburgh Postnatal Depression Scale (EPDS) with cut-off $>13$ was used to classify clinical depressive illness. Further, a focus group discussion was conducted with 20 women identified with the depression. Bivariate analysis with Odd's Ratio was used to test associations. Variables with a $p<0.05$ in multivariate were considered significant.

Result: Out of the 262 women, $33.6 \%$ were found to have prepartum depression as indicated by an EPDS score of $>13$. Women's gestational age in the second trimester $(87.5 \%)$ was statistically significantly associated with prepartum depression $(p<0.001)$. Income levels $<10,000 \mathrm{KES}(58 \%)$ were statistically significantly associated with prepartum depression $(p<0.001)$. Further, thematic analysis of qualitative data indicated that poverty, lack of social support, domestic violence, and unfriendly health care were major contributors to prepartum depression.

Conclusion: Significant numbers of pregnant women were found to experience depression. This prevalence rate indicates a high disease burden of women who live with depression, which is not diagnosed

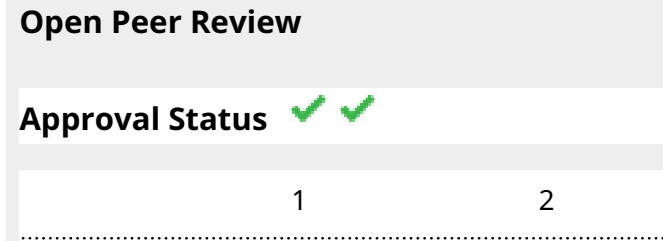

version 3

(revision)

10 Jun 2021

version 2

(revision)

16 Apr 2021

version 1

21 Dec 2020

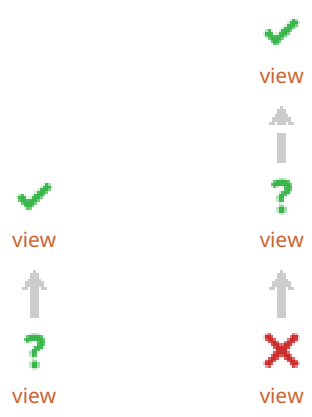

1. Irene Inwani, Kenyatta National Hospital,

Nairobi, Kenya

\section{Rahul Shidhaye ID, Pravara Institute of \\ Medical Sciences, Ahmednagar, India}

Any reports and responses or comments on the article can be found at the end of the article. 
because screening of depression is not done in primary health care centers. This study calls for a need and consideration for screening for perinatal depression in primary health care facilities, mainly in resource-poor areas. Interventions targeting means of resolving conflicts in families are highly needed. Such steps would help achieve key sustainable development goals where maternal and child health remains a key priority.

Keywords

Maternal , depression, risk factors, experiences, Kenya

Corresponding author: Beatrice A. Madeghe (bearecha@gmail.com)

Author roles: Madeghe BA: Conceptualization, Formal Analysis, Investigation, Methodology, Resources, Writing - Original Draft Preparation, Writing - Review \& Editing; Kogi-Makau W: Conceptualization, Supervision, Writing - Review \& Editing; Ngala S: Conceptualization, Software, Writing - Review \& Editing; Kumar M: Conceptualization, Supervision, Writing - Review \& Editing

Competing interests: No competing interests were disclosed.

Grant information: The author(s) declared that no grants were involved in supporting this work.

Copyright: ( $) 2020$ Madeghe BA et al. This is an open access article distributed under the terms of the Creative Commons Attribution License, which permits unrestricted use, distribution, and reproduction in any medium, provided the original work is properly cited.

How to cite this article: Madeghe BA, Kogi-Makau W, Ngala S and Kumar M. Risk factors and experiences of prepartum depression among pregnant women in urban- low income in Nairobi Kenya: a mixed-method study [version 1; peer review: 1 approved with reservations, 1 not approved] F1000Research 2020, 9:1495 https://doi.org/10.12688/f1000research.27434.1

First published: 21 Dec 2020, 9:1495 https://doi.org/10.12688/f1000research.27434.1 


\section{Introduction}

Prepartum depression has been identified as a serious health problem but is a neglected component of care for women during pregnancy ${ }^{1-3}$. While pregnancy is expected to be the most unique and happiest moments in a woman's life, to some women there is a different scenario filled with tears, fears, and confusion, including stress to severe depression ${ }^{4,5}$. Perinatal depression refers to mood disorders during pregnancy and/or after delivery within the first twelve months postpartum; thus, prepartum depression is a mood disorder during pregnancy ${ }^{6,7}$. Global prevalence indicates that at least one in ten women in developed countries and two in five women in the developing world develop depression during pregnancy ${ }^{8}$. The prevalence rates of prepartum depression range between $12.5-42 \%$ of women screened for depression symptoms in low and lower middleincome countries ${ }^{9,10}$. Systematic reviews that determined the occurrence and determinants of prepartum depression found prevalence rates that range from $15 \%$ to $65 \%$ globally ${ }^{4,11}$. In Kenya, prevalence estimates of depression are found at $32.9 \%$ among pregnant adolescents ${ }^{12}$, with postpartum depression prevalence rate of $13 \%{ }^{13}$.

Research evidence reveals that the stresses of life, especially around pregnancy and childbirth, can affect the emotions of women and behavior of many mothers, hence increasing the risk of depression during pregnancy and after childbirth ${ }^{14}$. Socio-determinants, i.e. the social conditions where people are born, grow, live, work, and age, influences their health outcomes $^{15,16}$. During pregnancy, maternal mental health is fundamental for the health of the mother and the infant's brain health and development; it needs to be prioritized early in the life course to prevent mental health problems later in life $^{1}$. Given this backdrop, this study aims to determine the magnitude of prepartum depression, and identify risk factors for prepartum depression, and picture real-life experiences of pregnant women of low-urban income in Nairobi, the capital city of Kenya.

\section{Methods}

\section{Study setting and participants}

This was a mixed-method cross-sectional study that involved pregnant women who attended antenatal care clinics, during the study period March 2019 to June 2019. Ethical approval was obtained from The Kenyatta National Hospital/University of Nairobi Ethical and Research Committee (KNH/UoN-ERC Ref: P56/02/2018). The study took place in two public health facilities in two urban low-income settlements, namely Kangemi and Kawangware. The two sites are both growing informal settlements, located on the outskirts of the Nairobi city center. They were chosen purposively because the antenatal clinics (ANC) at these health facilities receive a high volume of pregnant women. Eligibility criteria included all pregnant women aged 18 to 44 years who visited ANCs for antenatal check-up in Kawangware or Kangemi composed the study population.

This cross-sectional study was part of the baseline assessment of a longitudinal cohort study of pregnant women that targeted 100 depressed pregnant women, which examined the efficacy of dietary intervention for depression care among pregnant women in urban low-income Nairobi Kenya. To obtain the above sample size at baseline, consecutive sampling was used where every pregnant woman who came for checkup was assessed for depression; hence 262 pregnant women were recruited in this study.

\section{Data collection}

Quantitative data. Data were obtained from pregnant women by means of an interview administered questionnaire. All women who came to the ANCs and were queuing in the waiting room were approached to participate. The study purpose was explained to them that participation was voluntary, and refusal to participate will involve no penalty of benefits to which one is entitled at the clinic. The participants were assured about their privacy and confidentiality. After obtaining a written informed consent signed by the respondent based on willingness to participate, the interview commenced.

Socio-demographic characteristics questionnaire: Using a questionnaire, pregnant women provided data on sociodemographic characteristics, age, marital status, maternal education level, employment status, partner's occupation, monetary decision-making, and family monthly income.

Maternal depression questionnaire: Edinburgh Postnatal Depression Scale (EPDS), was used to assess maternal depression. The EPDS is a 10-item questionnaire in which women report on how they have been feeling in the past seven days ${ }^{17}$. EPDS, which has a Kiswahili translation version, has been validated for detecting depression in both prepartum and postpartum mothers in many countries, including Kenya ${ }^{18}$. EPDS is one of the most well-known and evaluated instruments for maternal depression and has demonstrated acceptable clinical utility as a screening tool. It has a sensitivity of $86 \%$, specificity of $78 \%$ and a positive predictive value of $73 \%{ }^{19,20}$. The depression scores were categorized into two levels; EPDS score higher than 13 indicated existence of clinical maternal depression ${ }^{17}$.

Qualitative data. A focus group discussion (FDG) was conducted with women who were identified as depressed, in order to get a deeper understanding of women's experiences during the present pregnancy. After identifying women as depressive in the questionnaire (above), we asked the pregnant women if they would be willing to participate in the FDG. Convenience sampling was used to select and invited the depressed pregnant women for FGD.

The aim of FGDs was to identify the causes of depression among pregnant women and the experiences around them. In this qualitative inquiry, 20 pregnant women with depressive symptoms (EPDS score cut-off score $>13$ ) were invited to participate. Two FGDs with a group of 10 participants were conducted from each site of Kangemi and Kawangware, respectively. Face to face discussion was conducted away from the health center by two female field researchers (BM and a research assistant) in a hired hall convenient for the women to discuss. BM has Master in Public Health, and the research assistant has MSc in 
Clinical Psychology. They were both trained on mental health quantitative and qualitative research methods. The relationship between researcher and pregnant women was established prior to the FDG. The FGD lasted for 60-90 minutes, and it was conducted in the Kiswahili language and was audio-recorded. The data was coded until when the ability to obtain additional new information was exhausted for the study purpose. The interview guide can be found in Extended data ${ }^{21}$.

\section{Data analysis}

Quantitative analysis. The filled questionnaires were checked for completeness, errors, and discrepancies; this was followed by data entry, cleaning, and analysis using SPSS version 22. Descriptive statistics such as percentage means and standard deviation were used to summarize the socio-demographic data. An EPDS score of $>13$ pointed the likelihood of the presence of clinical depressive illness. Independent variables were categorized to analyzed, the association between independent and outcome variable, using a bivariate analysis odds ratio (OR) with 95\% confidence interval (CI). Those variables that were associated with $\mathrm{p}<0.001$ in the bivariate analysis were entered into multivariate analysis. Variables with $\mathrm{p}<0.05$ in the multivariate analysis were considered to be significant.

Qualitative analysis. The FDGs in Kiswahili was transcribed and translated into English at the same time. Thematic analysis was employed to process the data. Two coders (BM and a research assistant) were involved in the coding process. The study primarily followed the inductive approach and identified the emerging codes, and to some extent, the deductive approach was also used to determine the $\operatorname{codes}^{22}$. Coding was manually done, and finally, four major themes emerged from the discussion. Informed consent was obtained from participants in this research for future uses of data, such as publication, preservation, and long-term use of research data. Confidentiality was assured. The information collected was kept confidential. Serial numbers were used instead of a name.

\section{Results}

Socio-demographic characteristics of pregnant women in the urban low-income settlement

In total 262 women responded to the questionnaire, 134 from Kangemi and 128 from Kawangware. The mean (SD) age of the 262 women was $25.3 \pm 5.0$ years (range, $18-44$ years). The majority of the women $(82 \%)$ were married, with $29.8 \%$ having less than high school education and $14 \%$ had tertiary level education. About $79.4 \%$ of the women had no employment but depended on their partners or parents, only $20.6 \%$ were employed. Slightly less than half of the women $(43 \%)$ were first-time mothers, while $70 \%$ of them were in their second trimester during baseline assessment. Almost all the women (98\%) owned a basic personal phone, and slightly less than three quarters owned a television $(73 \%)$. The mean (SD) income level was 10845.8 Kenyan shillings (KES) per month, and almost half of the women (49.6\%) lived on an income less than KES 15,000, equivalent of 150 USD per month, while two-fifths of the women (38.9\%) had their husbands make decisions on household finances (Table 1).
Table 1. Socio-demographics characteristics of pregnant women from urban low-income settlements in Nairobi, Kenya.

\begin{tabular}{|c|c|c|c|}
\hline Variable & Category & $\begin{array}{l}\text { Frequency } \\
(\mathrm{N}=262)\end{array}$ & $\begin{array}{c}\text { Percentage } \\
(\%)\end{array}$ \\
\hline \multirow[t]{2}{*}{ Age (years) } & $18-24$ & 134 & 51.1 \\
\hline & $25-42$ & 128 & 48.9 \\
\hline Age (years) & Mean (SD) & 25.3 & 5.0 \\
\hline \multirow[t]{2}{*}{ Marital status } & Single/lives alone & 48 & 18.3 \\
\hline & $\begin{array}{l}\text { Married/lives } \\
\text { with a partner }\end{array}$ & 214 & 81.7 \\
\hline \multirow{3}{*}{$\begin{array}{l}\text { Gestational } \\
\text { age }\end{array}$} & First trimester & 24 & 9.2 \\
\hline & Second trimester & 182 & 69.5 \\
\hline & Third trimester & 56 & 21.4 \\
\hline \multirow[t]{2}{*}{ Employment } & No & 208 & 79.4 \\
\hline & Yes & 54 & 20.6 \\
\hline \multirow[t]{3}{*}{$\begin{array}{l}\text { Education } \\
\text { level }\end{array}$} & $\begin{array}{l}\text { Primary and } \\
\text { below }\end{array}$ & 78 & 29.8 \\
\hline & Secondary & 148 & 56.5 \\
\hline & Tertiary & 36 & 13.7 \\
\hline \multirow{3}{*}{$\begin{array}{l}\text { Decision } \\
\text { maker }\end{array}$} & Both & 110 & 42.0 \\
\hline & Husband & 102 & 38.9 \\
\hline & Others & 50 & 19.1 \\
\hline \multirow{4}{*}{$\begin{array}{l}\text { Number } \\
\text { of children } \\
\text { under } 18 \\
\text { years }\end{array}$} & None & 112 & 42.7 \\
\hline & One & 80 & 30.5 \\
\hline & Two & 49 & 18.7 \\
\hline & Three and above & 21 & 8.0 \\
\hline $\begin{array}{l}\text { Income per } \\
\text { month (KES) }\end{array}$ & Mean (SD) & 10845.8 & 5005.6 \\
\hline \multirow{4}{*}{$\begin{array}{l}\text { Income per } \\
\text { month (KES) }\end{array}$} & $\leq 5000$ & 31 & 11.8 \\
\hline & $5,001-15,000$ & 130 & 49.6 \\
\hline & $10,001-15,000$ & 69 & 26.3 \\
\hline & $\geq 15,001$ & 32 & 12.2 \\
\hline \multirow[t]{2}{*}{ Owns mobile } & Yes & 256 & 97.7 \\
\hline & No & 6 & 2.3 \\
\hline \multirow[t]{2}{*}{ Owns radio } & Yes & 213 & 81.3 \\
\hline & No & 49 & 18.7 \\
\hline \multirow[t]{2}{*}{ Owns TV } & Yes & 192 & 73.3 \\
\hline & No & 70 & 26.7 \\
\hline \multirow[t]{2}{*}{ Owns laptop } & Yes & 25 & 9.5 \\
\hline & No & 237 & 90.5 \\
\hline
\end{tabular}


Levels of prepartum depression among pregnant women in urban low-income

Guided by the EPDS scoring system, the 10 items generated a depression score ranging from 0 to 30 . The depression scores were categorized into two levels (depressed and not depressed). A score greater than 13 indicated the existence of prepartum depression of various severities

Out of the 262 women, about a third $(33.6 \%$; 95\% CI 27.9-40.7) had depression as indicated by EPDS $>13$ (Figure 1). Suicidal Ideation (EPDS item 10) revealed that $24 \%$ of pregnant women had some suicidal ideation. The mean (SD) EPDS score was 11.1, interquartile range of 10 with a minimum score of 0 and a maximum score of 26 . When the socio-demographic characteristics were compared between depressed women and those not depressed, results showed that women's gestation age in the second trimester $(87.5 \%)$ was statistically significantly associated with maternal depression (OR 3.37; 95\% CI 1.60-7.10; $\mathrm{p}<0.001)$. Income levels was also statistically significantly associated with maternal depression where women (58\%) with income level $<10,000$ KES were depressed (OR 0.39; 95\% CI 0.23-0.66; $\mathrm{p}<0.001$; Table 2).

\section{Qualitative results}

Participants were aged from 18 to 44 years, and these women all had an EPDS score of 13-25 and were in their second trimesters. Table 3 provides participant's characteristics in the FGDs.

The qualitative results from the FDGs were categorized into four major themes: poverty - manifested through a financial struggle, unemployment and food insecurity; social support women reported inadequate support from their partners/husbands, the lack of a trustworthy person/friend who they could share their worries, loneliness, living far from family members, and feeling neglected; marital disharmony - issues of domestic violence (physical abuse and psychological/emotional abuse), and separation/divorce were reported; trauma experiences - women reported fear and worries about childbirth and birth outcome, considering that most of them were first-time mothers, and some women reported a previous loss of a child, previous birth difficulties, and fear of facing health care providers. Each of these themes are discussed in detail below.

Poverty. Poverty is the root cause of stress and prepartum depression and contributes to other risk factors of depression. Women reported having not enough making and everything seeming difficult because of this. The three subthemes identified were financial struggles, food insecurity, and lack of employment.

\section{Financial struggles}

Pregnant women reported having financial struggles because they have no income, or their partner not being employed, so it becomes so difficult for them to do things.

"I don't have a job, and I'm pregnant, and my husband doesn't have a job, and we live that way looking here and there; we are supposed to pay rent, food, and different kinds of needs. So you live with questions and start questioning yourself." Participant 20

"Lack of money; If I have money in my pocket, I would be just fine.” Participant 15

"By the way, you stay in the house; maybe you lack something, and when you ask for it, and the husband doesn't have money, so he begins to become harsh, then it results in quarreling, just that." Participant 5

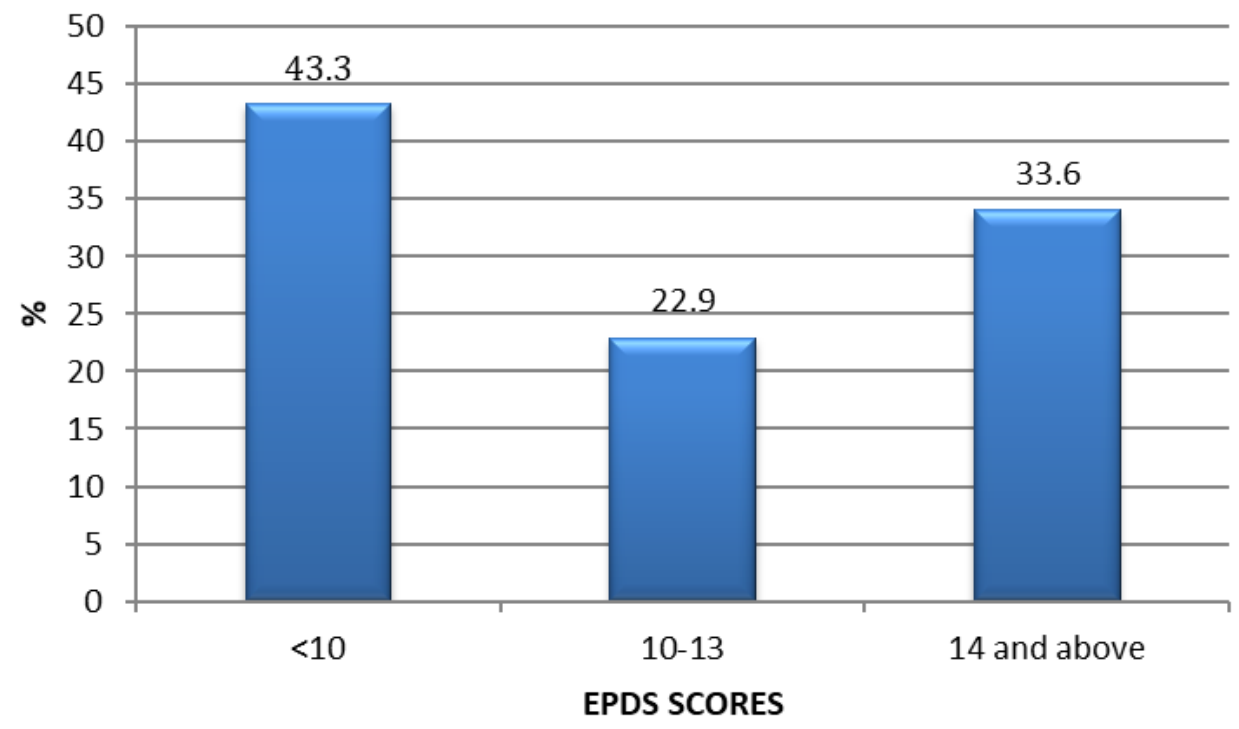

Figure 1. Prepartum depression among pregnant women in urban low income Nairobi -Kenya. 


\begin{tabular}{|c|c|c|c|c|c|}
\hline \multirow[t]{2}{*}{ Variable } & \multirow[t]{2}{*}{ Category } & \multirow{2}{*}{$\begin{array}{l}\text { Depressed } \\
\qquad \begin{array}{c}\mathrm{N}=174 \\
(\%)\end{array}\end{array}$} & \multirow{2}{*}{$\begin{array}{l}\text { Not depressed } \\
\qquad \begin{array}{c}\mathrm{N}=88 \\
(\%)\end{array}\end{array}$} & \multirow[t]{2}{*}{ OR $(95 \% \mathrm{CI})$} & \multirow[t]{2}{*}{ P-value } \\
\hline & & & & & \\
\hline \multirow[t]{2}{*}{ Age (years) } & $18-24$ & 49.4 & 54.5 & $0.83(0.44-1.39)$ & 0.484 \\
\hline & $25-42$ & 50.6 & 45.5 & & \\
\hline \multirow[t]{2}{*}{ Marital status } & Single & 17.8 & 19.3 & $0.90(0.47-1.74)$ & 0.767 \\
\hline & Married & 82.2 & 80.7 & & \\
\hline \multirow[t]{3}{*}{ Gestational age } & First trimester & 13.81 & 4.5 & $2.76(0.94-8.07)$ & 0.064 \\
\hline & Second trimester & 60.3 & 87.5 & $3.37(1.60-7.10)$ & 0.001 \\
\hline & Third trimester & 22.9 & 8.0 & & \\
\hline \multirow[t]{2}{*}{ Employment } & No & 77.0 & 84.1 & $0.63(0.32-1.24)$ & 0.181 \\
\hline & Yes & 23.0 & 15.9 & & \\
\hline \multirow[t]{3}{*}{ Education level } & $\leq$ Primary & 30.5 & 28.0 & $0.74(0.33-1.69)$ & 0.475 \\
\hline & Secondary & 55.7 & 58.0 & $0.98(0.47-2.08)$ & 0.935 \\
\hline & Tertiary & 13.8 & 13.6 & & \\
\hline \multirow[t]{3}{*}{ Decision maker } & Both & 42.5 & 37.5 & & \\
\hline & Husband & 38.5 & 39.8 & $1.38(0.79-2.43)$ & 0.672 \\
\hline & Others & 19.0 & 22.7 & $1.55(0.78-3.09)$ & 0.212 \\
\hline \multirow[t]{2}{*}{ Income (KES) } & $<10,000$ & 35.1 & 58.0 & $\begin{array}{c}0.39(0.23- \\
0.66)\end{array}$ & 0.001 \\
\hline & $>10,000$ & 66.4 & 42.0 & & \\
\hline Household size & Mean $\pm S D$ & $2.95 \pm 1.20$ & $2.84 \pm 1.21$ & $0.82(0.66-1.02)$ & 0.475 \\
\hline
\end{tabular}

\section{Food insecurity}

Some pregnant women reported a lack of enough food, or sometimes basic food may be available, but the food that they crave during their pregnancy they cannot get.

"There is sometimes we don't have food, and there is nothing to eat." Participant 12

"My husband will leave without leaving me food to eat, and I'm pregnant, whereby I don't understand whatever is happening so that one usually bores me so much." Participant 17

"The problem is even if it is available yet my husband stresses me, how will I eat? You cannot." Participant 10

"Sometimes the basic food is available, but the food I feel like eating I can't get, I love and admire eating pizza, but there is not enough money to buy it." Participant 11

"When I ask him about house needs, he becomes harsh and doesn't understand me." Participant 6
Social support. Most of the pregnant women felt that they lacked emotional and financial support from the partners responsible for the pregnancy. In addition, some of the partners denied their pregnancy, and do not want to take any responsibilities.

"I stay with a family from my husband's side, and there is no support of any kind that they offer me, and the husband himself doesn't support me, so the people who support me are neighbors when I have a problem I tell them." Participant 2

"So before I got pregnant, he is the one who used to insist that I should give birth, and then he will marry me and such things, so when I got pregnant up to the moment, he still doesn't do what he said to me." Participant 4

"Was in the hospital they rang him saying, 'we want blood transfusion on her can you come and replace the blood?' He said 'I don't know EV.' He just talks rubbish." Participant 12 
Table 3. Characteristics of the participants in focus group discussions among pregnant women in urban low-income settlements in Nairobi, Kenya.

\begin{tabular}{|c|c|c|c|c|c|c|}
\hline $\begin{array}{l}\text { Participant } \\
\text { ID }\end{array}$ & $\begin{array}{l}\text { Age } \\
\text { (years) }\end{array}$ & $\begin{array}{l}\text { Marital } \\
\text { status }\end{array}$ & Education & $\begin{array}{l}\text { No. of } \\
\text { children }\end{array}$ & $\begin{array}{c}\text { Gestational } \\
\text { age }\end{array}$ & EPDS \\
\hline \multicolumn{7}{|l|}{ Kawangware } \\
\hline 1 & 19 & Single & Secondary & 1 & 6 & 14 \\
\hline 2 & 22 & Married & Primary & 1 & 4 & 18 \\
\hline 3 & 26 & Married & Primary & 0 & 5 & 17 \\
\hline 4 & 23 & Married & Secondary & 0 & 6 & 16 \\
\hline 5 & 20 & Married & Primary & 1 & 5 & 14 \\
\hline 6 & 21 & Married & Secondary & 0 & 5 & 15 \\
\hline 7 & 18 & Married & Primary & 0 & 5 & 14 \\
\hline 8 & 30 & Single & Collage & 2 & 6 & 16 \\
\hline 9 & 24 & Married & Secondary & 0 & 6 & 14 \\
\hline 10 & 33 & Married & Secondary & 1 & 6 & 19 \\
\hline \multicolumn{7}{|l|}{ Kangemi } \\
\hline 11 & 23 & Married & Primary & 1 & 5 & 14 \\
\hline 12 & 22 & Single & Secondary & 0 & 6 & 25 \\
\hline 13 & 25 & Married & Secondary & 0 & 6 & 18 \\
\hline 14 & 22 & Married & Secondary & 0 & 6 & 17 \\
\hline 15 & 30 & Married & College & 0 & 5 & 14 \\
\hline 16 & 21 & Married & Primary & 0 & 4 & 16 \\
\hline 17 & 33 & Married & Primary & 3 & 5 & 17 \\
\hline 18 & 23 & Married & Primary & 1 & 6 & 14 \\
\hline 19 & 24 & Single & Secondary & 0 & 5 & 19 \\
\hline 20 & 20 & Married & Secondary & 2 & 4 & 16 \\
\hline
\end{tabular}

"So for me, it is just to give birth and raise the baby by myself because he is not supporting" Participant 19

"My husband tells me, "what are you crying for? Just cry when you are tired you keep quiet”. Participant 5

Some women reported that they do not have a trusting person around them to share their worries and talk heart to heart. Living conditions in slums where people live in one plot, some neighbors are stubborn and like making fun to others, further contributing to stress, anger and depression. Some stay away from their family members, and so they feel they lack support.

“I don't have anybody to tell my story.” Participant 7

"They are available, but I have never trusted somebody so much.” Participant 5
"You cannot trust someone; maybe you can tell them your problems and think that it has ended there, but you will hear it with everybody." Participant 15

"Then there is another person whom you can tell and maybe feel that she is a friend, you sit with her and tell her; she also supports you as if she has pity over you, but maybe after you leave she is a type that laughs at you." Participant 16

Marital disharmony. In the FDGs, women reported hopelessness and helplessness around the experience of domestic abuse, which manifested as both physical and emotional abuse.

\section{Physical abuse}

"One day, my husband came and quarreled at me, and then he later slapped me, then pushed me. I fell on the 
table and hit my stomach. I started feeling pain on the stomach and thought my baby in my belly was hurt." Participant 6

"My husband has a lot of disrespect whereby he sometimes spends a night out when he comes back and ask him where he was then at that point we start a big fight, and he will leave without leaving you food usually that bores me so much.” Participant 17

Some women defend themselves.

"Yes; whenever he starts, we just hit each other, there is no sparing him; so he also fears me, I have a lot of energy, and he cannot quarrel with me so much." Participant 14

Sometimes women are forced to stay with abusive partners even if they are beaten as they cannot sustain themselves.

"If you go tell parents you're told that "you cannot live a life with a husband without being beaten" Participant 3

“When you leave, where will you go?” Participant 9

"I don't have a job; don't have money; if I have had a job and money would get myself out. Where will I stay?" Participant 11

\section{Psychological abuse}

Women reported being psychologically abused, with many partners not wanting to offer emotional support to their wives.

"He is keeping quiet, if I don't talk, he cannot talk, and it hurts me so much.” Participant 19

"He said that he will beat me and that he is not the one responsible for the pregnancy, then he said that I abort, but I abandoned him." Participant 13

"That one he doesn't want to talk when you are tired and tell him 'Today I am not feeling well', he tells you 'it's up to you'. Participant 9

\section{Separation/Divorce}

Some women experienced separation or divorce.

"I don't stay with him too, but he is so contemptuous; he cannot even offer you support, he has even blacklisted my number." Participant 12

"I don't know how to put it, but we parted ways those days when I was the first month, so all along I have been surviving, and I have become used." Participant 8

Trauma experiences. Some women had previous trauma experiences, such as loss of a child and difficult birth.

"Fear of how it will be when I go for delivery you don't know if your child will be alive." Participant 3
"I fear how that situation will be, so my mind is tormented by the day that I will go to deliver." Participant 7

"I fear delivery that is the stress I have, since I have never had a baby, people tell me but it frightens me" Participant 1

Some women feel that health care is unfriendly. When they go to the clinic, nothing is explained to them, even during a physical examination. For example, pregnant women are not given any feedback about how they are doing, or if their babies are growing well. They reported that they are dismissed without any information given to them, only the date to come back for checkup is provided. Therefore, the women reported that health care itself is a source of stress.

"They press my belly so hard and painful, and they tell me go you are done, and another one is called; you are not told how your baby is doing, so I don't understand." Participant 6

\section{Discussion}

In our study, $33.6 \%$ of pregnant women in the study had maternal depression, as assessed by EPDS, which was associated with low-income and gestational age, specifically in the second trimester. This prevalence rate indicates a high number of women who live with depression and calls for interventions to support women with this condition. This estimate lies within the wide range of prior prepartum prevalence rates of depressive symptoms (12.5-42\%) among pregnant women in low and middle-income countries ${ }^{9,10}$. Our findings revealed relatively similar prevalence rates to the study by De Oliveira et al. ${ }^{11}$, who found $37.5 \%$ depression prevalence among Hispanic pregnant women in South Florida using PHQ-9. A study by Sheeba et al. ${ }^{23}$ in Ethiopia found a prevalence rate of $35.7 \%$ among pregnant women using EPDS $>13$. Likewise, among Chinese women a prevalence rate of $28.5 \%$ was found among pregnant women in late pregnancy using the Self-rating Depression $\mathrm{Scale}^{24}$. A study by Shrestha ${ }^{20}$ from Nepal reported a point prevalence of $18 \%$ among pregnant women using EPDS $\geq 10$. Another study in Ethiopia by Duko et al. ${ }^{25}$ found a prevalence rate of $21.5 \%$ among prenatal mothers using EPDS $\geq 13$.

Various prevalence estimates of prenatal depression have been reported in various countries. The differences in estimates could be due to methodological differences in the ways the studies were conducted, or the settings where the studies conducted, the timing of pregnancy, screening instruments used, and the cut-off values used to classify mothers as depressed (see reviews ${ }^{16,25-27}$ ). However, the most important thing to note is that all the studies show a significant prevalence of depression during pregnancy.

In our study, low-income and gestational age, specifically during second trimester, were significantly statistically associated with prepartum depression. Furthermore, the qualitative findings revealed poverty to be the primary determinant of maternal depression, especially financial struggles due to lack of stable income and food insecurity. Our results have similarities with other studies in the literature, where the identified 
risk factors for prepartum depression include maternal age, socio-economic status ${ }^{15}$, domestic violence, social support, history of previous mental disorder ${ }^{23}$, and pregnancy-related complications $^{16}$. The study by Shrestha in Nepal reported higher odds for health problems, gestational age, sex preference, and spousal alcohol intake to be associated with depression ${ }^{20}$; these results are similar to our study where gestational age was associated with prepartum depression. Another study by Sheeba et al. in Ethiopia ${ }^{23}$ reported that age group, educational qualification and occupation were significant predictors of prenatal depression, and socio-economic status was not significantly associated with depression; these results contrast with our findings where age, education level, and occupation were not related to prepartum depression.

Qualitative findings revealed financial worries and psychosocial factors to be associated with prepartum depression. In our study, most of the study participants were young mothers who belonged to the low-income group, and most of them were first-time mothers. These women were unemployed and were entirely dependent on their spouses or partners and family members. It is hypothesized that low income increases the likelihood of poor living conditions; financial struggle influences personal relationships, leading to psychosocial stress ${ }^{23}$. This hypothesis agrees with our qualitative findings where poverty, including financial struggles and food insecurity, were associated with prepartum depression. The risk factors related to prepartum depression may not be similar. Some studies may find some risk factors associated with prepartum depression are not the same $\mathrm{e}^{16,25,26}$. This could be attributed due to cultural differences, population differences, study setting, and living conditions that cause people to experience different risk factors for prepartum depression.

\section{Strengths and limitations}

This study used mixed methods, both quantitative and qualitative. The qualitative part was useful in gaining a better understanding of the causes of prepartum depression and has complemented the quantitative part of the study to provide a fuller story. Prepartum depression has not been studied much in low and middle-income countries, contributing to a high disease burden. Therefore, our study focus on prepartum depression contributes to filling a knowledge gap and awareness to health-care providers, researchers, policymakers, and the public about the rates and risk factors of prepartum depression. However, due to reasons that the recruitment occurred at the ANC where the attendance rate is not $100 \%$ for all residents in the settlements, many women with depressive symptoms may not been reached, and even those who came to the ANC, not all of them were screened leading to underreporting of the cases hence the result cannot be generalized.

\section{Conclusion}

Considerable numbers of pregnant women, about a third of the women, were found to experience maternal depression in the urban-low income of Nairobi, Kenya. Our study findings indicate many women who live with maternal depression, which is neither diagnosed nor treated since the ANC do not carry out routine screening for prepartum depression. Therefore, women are suffering without adequate services or timely help. This study calls for urgent consideration of screening of perinatal depression at primary health care facilities so that women can get help through counseling and be provided with social support. We strongly feel that the ANC nurses and primary health care staff also need to be trained in delivering respectful, patient-centered services where the mental health of these vulnerable women is prioritized. Interventions targeting means of resolving conflicts and intimate partner violence are highly needed. This will contribute towards efforts on global mental health and sustainable development in prioritizing perinatal mental health and childhood mental health because acting early in the life course is crucial to preventing mental health problems later.

\section{Data availability}

Underlying data

Figshare: Socio-demography and Depression Questionnaire, https://doi.org/10.6084/m9.figshare.13265297.v128.

Figshare: Maternal Depression experiences FDG transcription, https://doi.org/10.6084/m9.figshare.13265549.v129.

\section{Extended data}

Figshare: Maternal Depression Experiences FDGs Interview guide, https://doi.org/10.6084/m9.figshare.13265420.v2 $2^{21}$.

Data are available under the terms of the Creative Commons Attribution 4.0 International license (CC-BY 4.0).

\section{Acknowledgments}

The authors would like to thank our study participant's pregnant women who attended the antennal clinic during the study period, numerous ANC nurses at Kangemi and Kawangware Health Centre. We thank the research assistants Ruth Mwaura and Theresia Mutisyo, for their valuable time and cooperation during fieldwork. We also acknowledge Albert Tele for his statistical support.
1. Patel V, Saxena S, Lund C, et al.: The Lancet Commission on global mental health and sustainable development. Lancet. 2018; 392(10157): 1553-1598. PubMed Abstract | Publisher Full Text

2. de Vargas Nunes Coll C, da Silveira MF, Bassani DG, et al.: Antenatal depressive symptoms among pregnant women: Evidence from a Southern Brazilian population-based cohort study. J Affect Disord. 2017; 209: 140-146. PubMed Abstract | Publisher Full Text | Free Full Text

3. Ogbo FA, Eastwood J, Hendry A, et al.: Determinants of antenatal depression 
and postnatal depression in Australia. BMC Psychiatry. 2018; 18(1): 49. PubMed Abstract | Publisher Full Text | Free Full Text

4. Fisher J, de Mello MC, Patel V, et al.: Prevalence and determinants of common perinatal mental disorders in women in low- and lower-middle-income countries: a systematic review. Bull World Health Organ. 2012; 90(2): 139G-149G.

PubMed Abstract | Publisher Full Text | Free Full Text

5. Barker ED, Kirkham N, Ng J, et al:: Prenatal maternal depression symptoms and nutrition, and child cognitive function. Br J Psychiatry. 2013; 203(6): 417-421.

PubMed Abstract | Publisher Full Text | Free Full Text

6. Ford E, Lee S, Shakespeare J, et al.: Diagnosis and management of perinatal depression and anxiety in general practice: a meta-synthesis of qualitative studies. Br J Gen Pract. 2017; 67(661): e538-e546.

PubMed Abstract | Publisher Full Text | Free Full Text

7. Leung BMY, Kaplan BJ: Perinatal depression: prevalence, risks, and the nutrition link--a review of the literature. J Am Diet Assoc. 2009; 109(9): $1566-1575$.

PubMed Abstract | Publisher Full Text

8. Mossie TB, Sibhatu AK, Dargie A et al: Prevalence of Antenatal Depressive Symptoms and Associated Factors among Pregnant Women in Maichew, North Ethiopia: An Institution Based Study. Ethiop J Health Sci. 2017; 27(1): 59-66.

PubMed Abstract | Publisher Full Text | Free Full Text

9. WHO-UNFPA: Maternal mental health and child health and development in low and middle income countries. Geneva, Switzerland. 2008. Reference Source

10. Woldetsadik AM, Ayele AN, Roba AE, et al.: Prevalence of common mental disorder and associated factors among pregnant women in South-East Ethiopia, 2017: a community based cross-sectional study. Reprod Health. 2019; 16(1): 173

PubMed Abstract | Publisher Full Text | Free Full Text

11. De Oliveira G, Cianelli R, Gattamorta K, et al.: Social Determinants of Depression Among Hispanic Women. J Am Psychiatr Nurses Assoc. 2017; 23(1): $28-36$.

PubMed Abstract | Publisher Full Text | Free Full Text

12. Osok J, Kigamwa P, Stoep AV, et al.: Depression and its psychosocial risk factors in pregnant Kenyan adolescents: a cross-sectional study in a community health Centre of Nairobi. BMC Psychiatry. 2018; 18(1): 136. PubMed Abstract | Publisher Full Text | Free Full Text

13. Madeghe BA, Kimani VN, Stoep AV, et al.: Postpartum depression and infant feeding practices in a low income urban settlement in Nairobi-Kenya. BMC Res Notes. 2016; 9(1): 506

PubMed Abstract | Publisher Full Text | Free Full Text

14. Govender D, Naidoo S, Taylor M: Antenatal and Postpartum Depression: Prevalence and Associated Risk Factors among Adolescents' in KwaZuluNatal, South Africa. Depress Res Treat. 2020; 2020: 5364521.

PubMed Abstract | Publisher Full Text | Free Full Text

15. World Health Organization: A Conceptual Framework for Action on the Social Determinant of Health. 2008.

Reference Source

16. World Health Organization: Thinking Healthy: A manual for psychosocial management of perinatal depression. WHO, Community Health Workers
Version. 2015.

Reference Source

17. Cox JL, Holden JM, Sagovsky R: Detection of postnatal depression. Development of the 10-item Edinburgh Postnatal Depression Scale. $\mathrm{Br}$ J Psychiatry. 1987; 150: 782-6.

PubMed Abstract | Publisher Full Text

18. Kumar M, Ongeri L, Mathai M, et al.: Translation of EPDS Questionnaire into Kiswahili: Understanding the Cross-Cultural and Translation Issues in Mental Health Research. J Pregnancy Child Health. 2015; 2(1): 1000134. PubMed Abstract | Publisher Full Text | Free Full Text

19. Tesfaye $M$, Hanlon C, Wondimagegn $D$, et al.: Detecting postnatal common mental disorders in Addis Ababa, Ethiopia: validation of the Edinburgh Postnatal Depression Scale and Kessler Scales. J Affect Disord. 2010; 122(1-2): 102-8.

PubMed Abstract | Publisher Full Text

20. Joshi $D$, Shrestha $S$, Shrestha N: Understanding the antepartum depressive symptoms and its risk factors among the pregnant women visiting public health facilities of Nepal. PLoS One. 2019; 14(4): e0214992. PubMed Abstract | Publisher Full Text | Free Full Text

21. Madeghe B, Kogi-Makau W, Kumar M, et al.: Maternal Depression Experiences FDGs Interview guide. figshare. Dataset. 2020.

http://www.doi.org/10.6084/m9.figshare.13265420.v2

22. Ibrahim M: Thematic Analysis : A Critical Review of Its Process and Evaluation. WEI International European AcademicConference Proceedings. 2012; 1: 8-21.

Reference Source

23. Sheeba B, Nath A, Metgud CS, et al.: Prenatal Depression and Its Associated Risk Factors Among Pregnant Women in Bangalore: A Hospital Based Prevalence Study. Front Public Health. 2019; 7: 108. PubMed Abstract | Publisher Full Text | Free Full Text

24. Zeng Y, Cui Y, Li J: Prevalence and predictors of antenatal depressive symptoms among Chinese women in their third trimester: a crosssectional survey. BMC Psychiatry. 2015; 15(1): 66

PubMed Abstract | Publisher Full Text | Free Full Text

25. Duko B, Ayano G, Bedaso A: Depression among pregnant women and associated factors in Hawassa city, Ethiopia: an institution-based crosssectional study. Reprod Health. 2019; 16(1): 25 PubMed Abstract | Publisher Full Text | Free Full Text

26. Abebe A, Tesfaw $\mathrm{G}$, Mulat $\mathrm{H}$, et al:: Postpartum depression and associated factors among mothers in Bahir Dar Town, Northwest Ethiopia. Ann Gen Psychiatry. 2019; 18(1): 19.

PubMed Abstract | Publisher Full Text | Free Full Text

27. Rashid A, Mohd R: Poor social support as a risk factor for antenatal depressive symptoms among women attending public antennal clinics in Penang, Malaysia. Reprod Health. 2017; 14(1): 144 PubMed Abstract | Publisher Full Text | Free Full Text

28. Madeghe B, Kogi-Makau W, Kumar M, et al:: Socio-demography and Depression Questionnaire. figshare. Dataset. 2020 http://www.doi.org/10.6084/m9.figshare.13265297.v1

29. Madeghe B, Kogi-Makau W, Kumar M, et al.: Maternal Depression experiences FDG transcription. figshare. Dataset. 2020. http://www.doi.org/10.6084/m9.figshare.13265549.v1 


\section{Open Peer Review}

\section{Current Peer Review Status: ? $\mathrm{X}$}

\section{Version 1}

Reviewer Report 04 February 2021

https://doi.org/10.5256/f1000research.30318.r76448

(C) 2021 Shidhaye R. This is an open access peer review report distributed under the terms of the Creative Commons Attribution License, which permits unrestricted use, distribution, and reproduction in any medium, provided the original work is properly cited.

\section{Rahul Shidhaye}

Pravara Institute of Medical Sciences, Ahmednagar, Maharashtra, India

In this paper titled, 'Risk factors and experiences of prepartum depression among pregnant women in urban-low income in Nairobi Kenya: a mixed methods study,' Madeghe and colleagues present the prevalence of prepartum depression, risk factors, and real-life experiences of depression among pregnant women. There are few concerns that need to be addressed and some suggestions to further improve this paper.

1. Title: It will be better to use the term 'antenatal depression' instead of 'prepartum depression' as the former is more commonly used in the literature. A quick pubmed search returned 609 articles for the term, 'antenatal depression' compared to 9 results when 'prepartum depression' was used. In case you agree with this suggestion, please make the changes throughout the draft. I assume you wish to say urban-low income settlements/setting? Please add an appropriate word in the title. Prepartum depression will be present ONLY in pregnant women. It will be good to say either, 'prepartum/antenatal depression in urban low......' or 'depression among pregnant women in urban low.....'

2. Abstract: It is mentioned, 'Women's gestational age in the second trimester (87.5\%) was statistically significantly associated with prepartum depression $(p<0.001)$.' Please can you provide the measure of association (odds ratio) to support this statement? It is not clear what $87.5 \%$ means. Is it that $87.5 \%$ of women in their second trimester had depression? I have the same comment for the next statement in the abstract on income level.

3. Sample size: Please provide the rationale for recruiting 262 pregnant women in this study.

4. It will be good to provide the reference for the cohort study mentioned in the methods section.

5. Did you use any conceptual framework or prior literature to select the socio-demographic characteristics? A number of factors such as domestic violence, gender preference of the child, and nutritional status of women are not included. Please clarify. 
6. Generally, the cut-off of $11 / 12$ is used for EPDS. Please clarify the reason for choosing $12 / 13$ as the cut-off.

7. The following sentence is not clear, 'The data was coded until when the ability to obtain additional new information was exhausted for the study purpose.'

8. How many women were approached and what proportion of them consented to participate in the study? Please provide these details in the first paragraph of the results.

9. Although $33.6 \%$ of women had depression, table 2 mentions 174 women as depressed. Please check.

10. Please provide actual $\mathrm{n}$ for each of the variables.

11. The percentages presented in table 2 make very little sense. The readers will be interested in knowing the proportion of women who screened positive for depression for one level of a variable compared to another level of the same variable. To illustrate this, it will be good to know what proportion of women in the age group of 18-24 screened positive for depression and also the proportion of women in the age group of 25-42 who screened positive for depression. The current numbers do not provide that information.

12. It seems that lower income level was a protective factor and resulted in lower odds of depression (OR: $0.39,95 \%$ CI 0.23-0.66). This completely contradicts the findings from your qualitative study as well as from the past literature.

13. Please present the findings related to the univariable association of each of the explanatory variables with the outcome. I assume that the findings in table 2 are that of multivariable association? Please clarify.

14. The analysis undertaken is simple/univariable and multiple/multivariable logistic regression and not multivariate regression. Please correct.

15. One of the important limitations is the cross-sectional nature of this study which precludes any causal inferences. This needs to be included in the limitations.

16. It is also likely to have confounding bias as the data on key explanatory variables is not included.

17. The use of a screening tool for depression (EPDS) also needs to be included as one of the limitations.

18. Please read the paper carefully to address the grammatical errors.

Is the work clearly and accurately presented and does it cite the current literature? Partly

Is the study design appropriate and is the work technically sound? 
Partly

Are sufficient details of methods and analysis provided to allow replication by others? Yes

If applicable, is the statistical analysis and its interpretation appropriate? Partly

Are all the source data underlying the results available to ensure full reproducibility? Yes

Are the conclusions drawn adequately supported by the results? Partly

Competing Interests: No competing interests were disclosed.

Reviewer Expertise: Psychiatric epidemiology, perinatal mental health, implementation science I confirm that I have read this submission and believe that I have an appropriate level of expertise to state that I do not consider it to be of an acceptable scientific standard, for reasons outlined above.

Author Response 07 Apr 2021

Beatrice Madeghe, University of Nairobi, Nairobi, Kenya

Reviewer 2: Comments and responses

1. Title: It will be better to use the term 'antenatal depression' instead of 'prepartum depression' as the former is more commonly used in the literature. A quick PubMed search returned 609 articles for the term, 'antenatal depression' compared to 9 results when 'prepartum depression' was used. In case you agree with this suggestion, please make the changes throughout the draft. I assume you wish to say urban-low income settlements/setting? Please add an appropriate word in the title. Prepartum depression will be present ONLY in pregnant women. It will be good to say either, 'prepartum/antenatal depression in urban low......' or 'depression among pregnant women in urban low....?

Responses:-

Thank you for this suggestion and it is true pre-partum is not commonly used. I request to maintain the prepartum term because I have defined it and it has the same meaning as prenatal. I have maintained it throughout the text. I have structured the title, and I have added the words settlements as advised, now the title read as:-"Risk factors and experiences of prepartum depression in urban-low income settlements Nairobi-Kenya: a mixed-method study" see page 1.

2. Abstract: It is mentioned, 'Women's gestational age in the second trimester (87.5\%) was statistically significantly associated with prepartum depression $(p<0.001)$.' Please can you provide the measure of association (odds ratio) to support this statement? It is not clear what $87.5 \%$ means. Is it that $87.5 \%$ of women in their second trimester had depression? I 
have the same comment for the next statement in the abstract on income level?

Response: -

This was revised. I have provided the measures of associations to support the statements in the abstract and text as follows:- Women's gestational age was statistically significantly associated with prepartum depression [OR 3.37; (95\% C.I 1.60 - 7.10); $p<0.001$ ]. Income levels $<10,000$ KES was statistically significantly associated with prepartum depression [OR 0.39; (95\%; C.I $0.23-0.66) ; p<0.001$. See abstract.

3.Sample size: Please provide the rationale for recruiting 262 pregnant women in this study?

Response: -

This was revised and explained in the text. The rationale for recruiting 262 women is because this was the baseline study for the intervention longitudinal study. So sample size was calculated using Sample size estimation for longitudinal designs with attrition (Diggle et al., 2002). We needed approximately $\underline{100}$ subjects in each group, where $\underline{50}$ would be the intervention and $\underline{50}$ would be the intervention group. Therefore to obtain the above sample of women, we consecutively screened 262 pregnant women at baseline and obtained 100 depressed pregnant women. See method.

4. It will be good to provide the reference for the cohort study mentioned in the methods section?

Response: -

Thank you for this suggestion, the intervention results for this study are not yet published and still under review, this was the baseline data that we are sharing, that's why we are unable to provide the reference cohort.

5. Did you use any conceptual framework or prior literature to select the socio-demographic characteristics? A number of factors such as domestic violence, gender preference of the child, and nutritional status of women are not included. Please clarify?

\section{Response: -}

Thank you for this comment. Yes, the literature guided the process of selecting the sociodemographic factors; in this study, the association between nutritional status and prepartum depression was studied in details, and the nutritional factors/status associated with prepartum depression were evaluated and discussed in another paper, which is still under review, we also conducted the focus group discussion to understanding the real-life experiences of depressed women. I admit that as a limitation to this study some contributing factors were not included in the sociodemographic questionnaire. However, in the focus group discussion, domestic violence came up and was captured as contributing factor for depression in this study. This limitation was added as the limitation of to study, that some factors such as child sex preference, spouse alcohol intake were not assessed.

6. Generally, the cut-off of $11 / 12$ is used for EPDS. Please clarify the reason for choosing $12 / 13$ as the cut-off?

Response: -

I used The Edinburgh Postnatal Depression Scale (EPDS). According to the scoring system of this tool, a score of 10 or greater indicates possible depression. Mothers who score above 13 are likely to be suffering from clinical depression of varying severity. The maximum 
score is 30.17

Therefore I followed the cut-off guidance provided in this scale where an EPDS, a score of 10 to 13 indicates possible depression of moderate severity, and a score of above 13 indicates clinical depression. In this study, all women who had EPDS SCORE of 10 to 13 were classified with possible depression, and those with EPDS scores of above 13 were classified as having clinical depression. Source: Cox, J.L., Holden, J.M., and Sagovsky, R. 1987.

7. The following sentence is not clear, 'The data was coded until when the ability to obtain additional new information was exhausted for the study purpose?

Response: -

The sentence was reviewed and made clear. Data was coded until all the information required for the study was exhausted. See FGDs results.

8. How many women were approached and what proportion of them consented to participate in the study? Please provide these details in the first paragraph of the results?

\section{Responses:-}

This section was revised and added to the text. This cross-sectional study was part of the baseline assessment of a longitudinal cohort study that targeted depressed pregnant women for intervention. Therefore the sample size was calculated using Sample size estimation for longitudinal designs with attrition (Diggle et al., 2002). We needed approximately 100 subjects. To obtain the above sample size at baseline, consecutive sampling was used where every pregnant woman who came for a checkup during the study period was assessed for depression as part of service delivery, hence 262 pregnant women were recruited which enabled a sample of 100 depressed women. See method.

9. Although $33.6 \%$ of women had depression, table 2 mentions 174 women as depressed. Please check?

\section{Responses: -}

Thank you for this comment. This was the mistake, the table was not labeled correctly. I have revised this table and the table has been labeled correctly.

10. Please provide actual $n$ for each of the variables?

Response: -

This has been revised the actual numbers in the table have been provided. See table 2 .

11. The percentages presented in table 2 make very little sense. The readers will be interested in knowing the proportion of women who screened positive for depression for one level of a variable compared to another level of the same variable. To illustrate this, it will be good to know what proportion of women in the age group of 18-24 screened positive for depression and also the proportion of women in the age group of 25-42 who screened positive for depression. The current numbers do not provide that information?

\section{Response: -}

This comment has been revised

I have provided the proportion of women who screened positive for depression for one level of a variable were compared to another level of the same variable. See table2.

12. It seems that a lower-income level was a protective factor and resulted in lower odds of 
depression (OR: $0.39,95 \%$ CI 0.23-0.66). This completely contradicts the findings from your qualitative study as well as from the past literature?

\section{Response: -}

This was an error in the labeling of table 2 , which caused results to read the opposite, this has been corrected, and the table labeled correctly. The result reads well that the lowerincome level is the risk factor for depression. See table 2.

13. Please present the findings related to the univariable association of each of the explanatory variables with the outcome. I assume that the findings in table 2 are that of multivariable association? Please clarify?

\section{Response:-}

Thank you for this comment, the factors that were significant in the univariable association were the same as in the multivariable association, so I only provided the multivariable table because the factor that was significant was the same. See data analysis.

14. The analysis undertaken is simple/univariable and multiple/multivariable logistic regression and not multivariate regression. Please correct?

\section{Response:-}

Thank you for this correction, I have corrected this error. The analysis undertaken was univariable and multivariable logistic regression. See data analysis.

15. One of the important limitations is the cross-sectional nature of this study which precludes any causal inferences. This needs to be included in the limitations?

\section{Response: -}

Thank you for this comment. This limitation has been added to this study, This study was a cross-sectional study and as a limitation, cross-sectional studies do not establish the causal relationship hence the limitation for this study. See study limitation.

16. It is also likely to have confounding bias as the data on key explanatory variables is not included?

\section{Response: -}

This section has been revised and added as a limitation to the study that, other possible confounding factors such as child preference, previous history of depression, and partner alcohol intake as a risk factor for depression were not assessed hence a limitation to this study. See study limitation.

17. The use of a screening tool for depression (EPDS) also needs to be included as one of the limitations?

\section{Response: -}

Thank you for this comment, this limitation was added to the text that; Although EPDS is an established and widely used screening tool for maternal depression with high specificity and sensitivity, it is not as a definitive diagnosis, hence the inherent limitation of using this tool. See study limitation.

18. Please read the paper carefully to address the grammatical errors?

Response: -

The paper was carefully read through and all possible grammatical errors addressed. Thank 
you

Competing Interests: None

Reviewer Report 25 January 2021

https://doi.org/10.5256/f1000research.30318.r76447

(C) 2021 Inwani I. This is an open access peer review report distributed under the terms of the Creative Commons Attribution License, which permits unrestricted use, distribution, and reproduction in any medium, provided the original work is properly cited.

\section{Irene Inwani}

Department of Pediatrics, Kenyatta National Hospital, Nairobi, Kenya

This manuscript addresses an important and to some extent neglected area of health care and research. It is a well written manuscript but there are areas that require some improvement as highlighted below:

1. What was the rationale of recruiting women aged 18 to 44 years only when we know age is a predictor of depression?

2. What was the justification for not including a sample from women identified as not depressed in the FGDs to understand if their experiences were similar to the sampled group?

3. Eligibility criteria in this study were only age and pregnancy. What criteria made participants not eligible for the study? Which confounding factors were considered?

4. Which quality assurance measures were put in place for qualitative data analysis?

5. Ethically; what happened to women found to have depression and especially those who had suicidal ideation as well as those experiencing violence?

6. Please check the following:

Age range in the text is 18-44 while in the tables it is 18-42

Table 1; what does the percentage of the mean age represent?

Parity is equated to the number of children below 18 years; this is erroneous, a 44 can have children above 18 and therefore be misclassified.

In the table the bands for income overlap, check.

Confirm the proportion of those earning less than 15000.

Revise subheadings to reflect the issue being addressed and leave out the population and settings which are described in the methods.

Reported range of depression score conflict some sections 0-30, others 0-26.

Table 2; confirm the totals $(\mathrm{N})$ for depressed and non-depressed. 
Table 3 categorize per site.

The qualitative data need to be reworked and triangulated appropriately with the quantitative data. The themes, example poverty and financial struggles are closely related and therefore need to see which quotes fit well in each theme.

Review the language in the quotes and generally in the qualitative section.

Discussion section; A good discussion but can be improved by focusing on the audience and key message built from the major findings. Check findings from other countries, regions and local which used a similar and different methodology, and if possible similar context.

Discuss some more weaknesses/limitations such as cross-sectional nature of the study therefore not able to establish a causal relationship, not having assessed other possible contributors to depression and neonatal outcomes

Is the work clearly and accurately presented and does it cite the current literature? Partly

Is the study design appropriate and is the work technically sound?

Yes

Are sufficient details of methods and analysis provided to allow replication by others? Yes

If applicable, is the statistical analysis and its interpretation appropriate? Partly

Are all the source data underlying the results available to ensure full reproducibility? Yes

Are the conclusions drawn adequately supported by the results?

Partly

Competing Interests: No competing interests were disclosed.

Reviewer Expertise: Pediatric, adolescents and maternal health.

I confirm that I have read this submission and believe that I have an appropriate level of expertise to confirm that it is of an acceptable scientific standard, however I have significant reservations, as outlined above.

Author Response 07 Apr 2021

Beatrice Madeghe, University of Nairobi, Nairobi, Kenya

Reviewer 1: Comments and responses

1. What was the rationale of recruiting women aged 18 to 44 years only when we know age is a predictor of depression? 
Response: - Thank you for this comment. This was a mistake and has been corrected in the text. The study participants included Women of reproductive age of 15-49 in Kenya. The actual age range of participants who were present and recruited in the study and their data analyzed had an age range of 18 to 42 . This has been corrected in the text. See method, Study participants.

2. What was the justification for not including a sample from women identified as not depressed in the FGDs to understand if their experiences were similar to the sampled group?

Responses: Thank you for this comment. This cross-sectional study was part of the baseline assessment of a longitudinal cohort study that targeted depressed pregnant women for intervention. The non-depressed women were not included in this study because the study interest was to understand the experiences of depression pregnant women to provide a way forward for an intervention study. Therefore we were interested in depressed pregnant women only, and it was necessary to find out their experiences for depression to get the starting point for the intervention. That's why non-depressed women were not included. However, I agree that including non-depressed women could be an advantage to know their experiences too. See FDGS section.

3. Eligibility criteria in this study were only age and pregnancy. What criteria made participants not eligible for the study? Which confounding factors were considered?

Response: - Thank you for this comment. The eligibility criteria were pregnant women who are depressed. As explained in the comment above, this study was part of the baseline data of an intervention study that targeted women of reproductive age and who are depressed so that they can be considered for $f$ intervention. So it included women who gave written informed consent and women who are not mentally disturbed to the extent of not giving correct information. See method

\section{Which quality assurance measures were put in place for qualitative data analysis?}

Responses: - We used the COREQ (Consolidated criteria for Reporting Qualitative research) Checklist, a 32-item checklist for interviews and focus groups. Developed from: Tong A, Sainsbury P, Craig J. Consolidated criteria for reporting qualitative research (COREQ). A checklist of items was included to report this qualitative research. Each of the items listed in this checklist was considered in the manuscript and was reported. The completed checklist was uploaded as part of my submission with this manuscript. See FGDs section

5. Ethically; what happened to women found to have depression and especially those who had suicidal ideation as well as those experiencing violence?

Responses: - This was revised and added to the text, All women who appeared to have suicidal ideation and those who were experiencing violence were referred to the mental health services available at the health facility for treatment, furthermore, the second part of the study was an intervention study so they were enrolled to proceed with the intervention 
study, See results depression levels.

\section{Please check the following:}

i. Age range in the text is $18-44$ while in the tables it is $18-42$ ?

Responses: - The actual age range of women recruited and their data analyzed had an age range of 18-42. See results, sociodemographic characteristics

ii. Table 1: What does the percentage of the mean age represent?

Response: - This was a mistake and the mistake has been corrected. See table 1

iii. Parity is equated to the number of children below 18 years; this is erroneous, a 44 can have children above 18 and therefore be misclassified?

Response: - Thank you for this comment. The age range of women recruited and their data analyzed in the study was 18 to 42 . None of them had a child above 18. As explained above the inclusion criteria has been corrected included women aged range of 15-49, but the actual age range of women obtained in the study was 18 - 42. Therefore there was no mixup, and the age range here was not equated with a number of children below 18 . See results.

iv. In the table the bands for income overlap, check. Confirm the proportion of those earning less than 1500 ?

Response: - This has been revised and the mistake and has been corrected in the table.

v. Reported range of depression score conflict some sections $0-30$, others $0-26$ ?

Response: - This has been clarified, Edinburgh Postnatal Depression Scale (EPDS), guided the scoring system 17 . EPDS has 10 questions which generate scores from 0 to 30 maximum. According to this tool, a score of 10/30 or greater indicates possible depression. Women who score above $13 / 30$ are likely to be suffering from clinical depression of varying severity. On the results, the actual scores of women screened in the study and their data analyzed had EPDS scores range of 0 -26. See results prevalence of Prepartum depression

vi. Table 2; confirm the totals ( $\mathrm{N}$ ) for depressed and non-depressed?

Response: - Thank you for this comment; Table 2 has been revised, the labeling error for table 2 has been corrected, the number of depressed and not depressed has been confirmed. See table3

vii. Table 3 categorize per site?

Response: - Table 3 has been revised and categorized per site, where the first table is depressed women from Kawangware and the second table is depressed women from Kangemi. See table 3. 
viii. The qualitative data need to be reworked and triangulated appropriately with the quantitative data. The themes, for example, poverty, and financial struggles are closely related and therefore need to see which quotes fit well in each theme?

Response: - Thank you for this comment. The themes were only four. Poverty is one theme that was - manifested through three sub-themes identified as financial struggle, unemployment, and food insecurity, so financial struggles were the sub-theme of poverty, not a different theme. The other theme was Social support: Marital disharmony and Trauma experiences and all have sub-themes, and their experiences were discussed in details in the quotes See qualitative results

ix. Review the language in the quotes and generally in the qualitative section?

Responses: - I have revised my best possible the quotes in the qualitative section

x. Discussion section; a good discussion but can be improved by focusing on the audience and key message built from the major findings. Check findings from other countries, regions, and local which used a similar and different methodology, and if possible similar context?

Response:-Thank you. The discussion section has been revised. I have tried to improve it as suggested. See discussion

xi. Discuss some more weaknesses/limitations that the cross-sectional nature of the study therefore not able to establish a causal relationship, not having assessed other possible contribution to depression and neonatal outcomes?

Responses Thank you for this comment. I have discussed more weakness/ limitations of the study and added to the text / other possible confounding factors such as child preference, previous history of depression, spouse alcohol intake as a risk factor for depression and neonatal outcomes were not assessed hence limitation to this study. Moreover, this was a cross-sectional study and as a limitation, cross-sectional studies do not establish the causal relationship hence the limitation for this study. See study limitation.

Competing Interests: None 
The benefits of publishing with F1000Research:

- Your article is published within days, with no editorial bias

- You can publish traditional articles, null/negative results, case reports, data notes and more

- The peer review process is transparent and collaborative

- Your article is indexed in PubMed after passing peer review

- Dedicated customer support at every stage

For pre-submission enquiries, contact research@f1000.com 